University for Business and Technology in Kosovo

UBT Knowledge Center

Oct 27th, 9:00 AM - 10:30 AM

\title{
Interaction of nanofibers with epithelial cells in the digestive system
}

Agron Millaku

University for Business and Technology

Follow this and additional works at: https://knowledgecenter.ubt-uni.net/conference

Part of the Food Science Commons

\section{Recommended Citation}

Millaku, Agron, "Interaction of nanofibers with epithelial cells in the digestive system" (2018). UBT International Conference. 174.

https://knowledgecenter.ubt-uni.net/conference/2018/all-events/174

This Event is brought to you for free and open access by the Publication and Journals at UBT Knowledge Center. It has been accepted for inclusion in UBT International Conference by an authorized administrator of UBT Knowledge Center. For more information, please contact knowledge.center@ubt-uni.net. 


\title{
Interaction of Nanofibers with Epithelial Cells in the Digestive System
}

\author{
Agron Millaku \\ UBT Higher Education Institution, Lagjja Kalabria p.n., Prishtinë, Kosovë \\ agron.millaku@ubt-uni.net
}

\begin{abstract}
I $n$ this study, we provide the evidence of interaction of tungsten nanofibres (NFWOx) with epithelial cells in the digestive tube of a test organism, woodlouse Porcellio Scaber studied by scanning electron microscopy (SEM). When the nanofibers enter the body through food, not all of them pass through the digestive system without an interaction. The result has provided us that in some areas nanofibers can react with epithelial cells on the digestive tube. Our results are consistent with the findings of many studies that have been made by many authors to show the risk of using nanofibers in the food industry but also more widely. We provided the evidence how the nanofibers can cause strong injuries on the epithelial cells in the digestive tube. Nanofibers can embed epithelial cells in the digestive tube, pierce the cell membrane and enter into the cells during the contraction period of peristalsis.
\end{abstract}

Keywords: Nanofibers interaction, Nanofibers injuries, Epithelial cells, Digestive tube.

\section{Introduction}

We agree that natural and artificial nanoparticles and nanofibers are present in our environment but data on their ecotoxicity and their interactions with cells of living organisms are insufficient [1-4].

Nanomaterials (NMs) are defined as materials that have structural features with at least one dimension of $100 \mathrm{~nm}$ or less, and include nanofilms and nanocoatings $(<100 \mathrm{~nm})$ in one dimension, nanotubes and nanowires $(<100 \mathrm{~nm})$ in two dimensions and Nanomaterials $(<100$ $\mathrm{nm})$ in three dimensions [5].

Natural nanomaterials are those that can occur naturally and may have been in the environment for millions of years e.g. fullerenes have been detected in geological deposits from the Cretaceous-Tertiary boundary [6]. In addition, carbon nanotubes (CNTs) and fullerenes were detected in Greenland in a melt sample from an ice core about 10,000 years old [7]. Nanodiamonds (NDs) have been also found in the Younger Drays Boundary Sediment Layer in North America [8]. During the past decade, interest in nanomaterials has risen dramatically because of their exceptional physico-chemical properties. Nanomaterials are characterized by large surface area- to-volume ratios, with about $40-50 \%$ of the atoms being on the surface; this results in greater reactivity, compared with bulk materials, or quantum effects. The ecotoxicity data on the effects of nanomaterials are in much need for the appropriate environmental risk assessment. Different documents already exist which deal with emerging and newly identified health risks [9-10].

Development of a hazard profile is the critical step in characterizing the potential safety of nanofibers, and the associated health and environmental hazards. A base set of hazard data has been suggested as a reference for characterization and prioritization of nanofibers [11]. 
For testing the effects of nanofibers on the digestive tube as a test organism we used woodlouse, invertebrate terrestrial isopod Porcellio scaber (Isopoda, Crustacea). This organism is very common and is used as a test model in many toxicology investigations. Terrestrial isopods are widely spread organisms, participating in decomposition of organic material in the leaf-litter layer, which is an indispensable process for ecosystem function [12].

Hepatopancreatic cells are directly exposed to substances in partly digested food, filtered from the proventriculus into the lumen of the hepatopancreas. Knowledge acquired in our laboratory on the responses of Porcellio scaber, such as food consumption and moulting to elevated concentrations of zinc or cadmium in their food in almost equal experimental conditions. Hepatopancreatic cells of metal-exposed animals displayed non-specific, stress indicating alterations such as cellular disintegration, the reduction of energetic reserves (lipid droplets, glycogen), and electron dense cytoplasm, ultrastructural alterations of granular endoplasmic reticulum, the Golgi complex and mitochondria.

The objective of this work was systematically study of the epithelial surface of control woodlouse animals and exposed group of woodlouse animals to tungsten nanofibers by scanning electron microscopy (SEM). The aim was to find the characteristic changes on the morphology of the digestive tube, shape and size of epithelium cells, shape and size of microvilli, the presence of bacteria or any changes that resulted as a consequence of the treatment with nanofibers.

In addition, this work was done to prove if the ingested nanofibers can cause morphological defects on the digestive gland epithelium of test animal P. scaber or damage the surface structure of the epithelium cells after exposure of animals to contaminated food with nanofibers and stress.

\section{Materials and methods}

Terrestrial isopods, including the species Porcellio scaber Latreille, 1809 (Crustacea: Isopoda), are frequently used organisms in toxicology and physiology (figure 1c). The evaluation of their responses to different physiological or experimental conditions is based on the knowledge about the characteristics of non-stressed animals. However, previous reports gave detailed descriptions of the morphology and the lipid content of the digestive gland epithelium (hepatopancreas) in animals of the species $P$. scaber exposed to different environmental conditions and feeding regimes [12]. In most terrestrial isopods, including P. scaber, the hepatopancreas is composed of four blind-ending tubes, which lie freely in the body cavity. The hepatopancreatic epithelium contains two cell types, i.e., the large B cells that project into the lumen of the hepatopancreas and the wedge-shaped $\mathrm{S}$ cells. Both cell types occur alternately in cross-sections (figure 1d).

The B cells are secretory and absorptive cells; they usually contain many lipid droplets (figure 2b)., glycogen, and store metal ions in granules. The $S$ cells accumulate metal ions, calcium, and urate. Morphological changes of B cells were first attributed to the 24-h digestive cycle and only recently evidence were given that also B-cells have a constant shape and size under normal physiological conditions(figure 2a,b,c,d). However, when the animals are subjected to stress, the response is reflected in the shape, size and lipid content. 

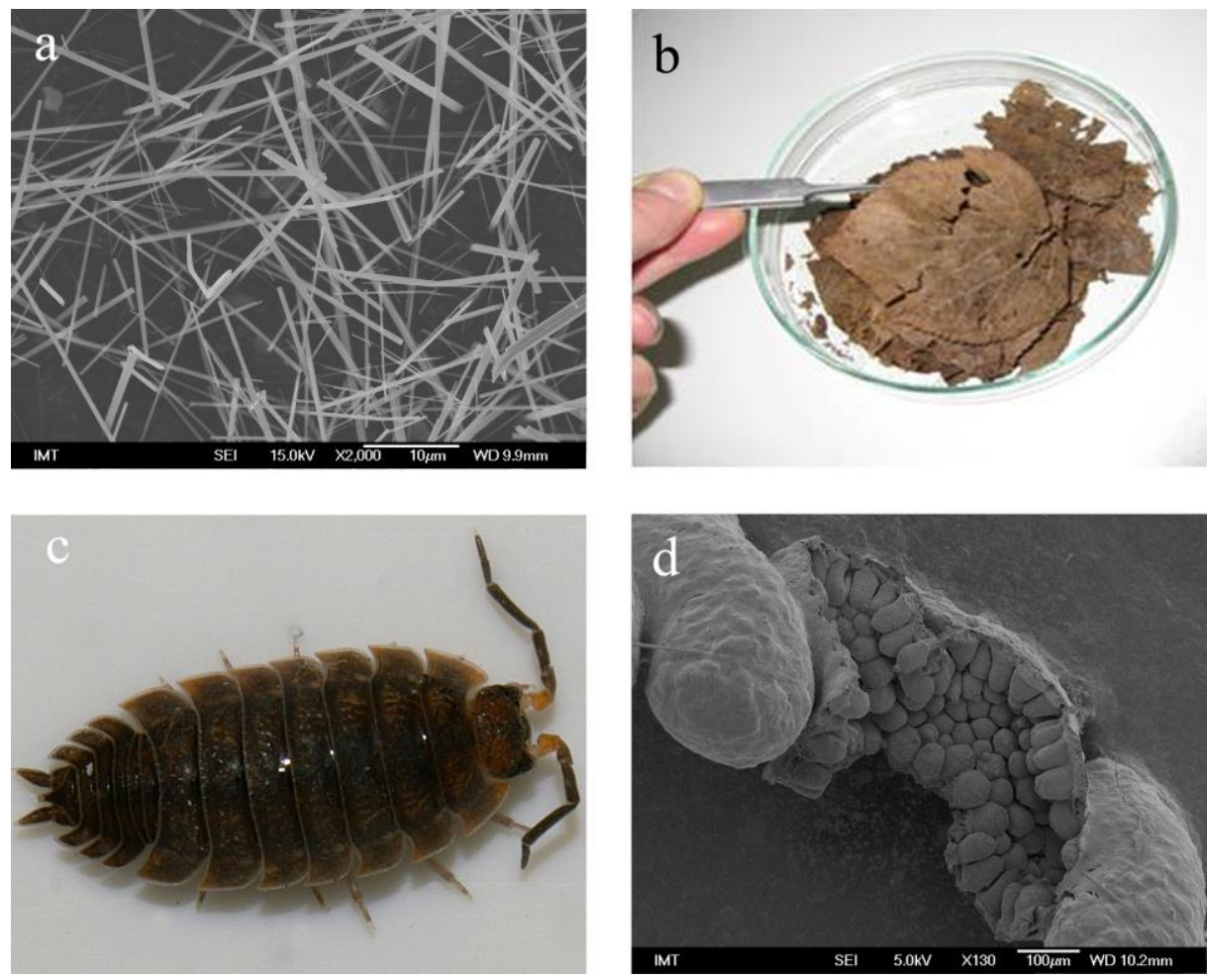

Figure 1. a) Tungsten oxide nanofibers. b) Food which is treated with nanofibers (leaves of Hazelnuts). c) Test organism Porcellio scaber; d) Hepatopancreas digestive tube prepared for SEM investigation.

The animals were collected under concrete blocks and pieces of decaying wood in three different locations near Ljubljana. The Areas was uncontaminated woodland and not inhabited. Animals were kept in a terrarium $(20 / 35 / 20 \mathrm{~cm})$ for acclimatization in period of three months. The terrarium was filled with a $2-5 \mathrm{~cm}$ layer of moistened sand and soil and a thick layer of partly decomposed hazelnut tree leaves (Corylus avellana). The substratum in the terrarium was heated to $80 \mathrm{C}^{\circ}$ for several hours to destroy predators (spiders) before the introduction of the isopods. The culture was kept at controlled room temperature $\left(21 \pm 1 \mathrm{C}^{\circ}\right)$, a 16:8-h light-dark photoperiod, and high humidity. Hazelnuts tree leaves were collected in uncontaminated woodland and dried at room temperature. Before the application of the Tungsten oxides nanofibers (figure 1a) dispersion, the leaves were kept in humid Petri dishes to facilitate the absorption of nanofibers dispersion (figure 1b). Afterward, the leaves were dried for 24 hours at room temperature. The tungsten oxides nanofibers were suspended in bidistilled water using a vortex and prepared fresh before each experiment. We applied $150 \mathrm{ml}$ of the dispersion per $100 \mathrm{mg}$ of leaf onto the lower leaf surfaces. Animals in the control group were fed up with leaves prepared in the same way but treated with the bidistilled water only. 

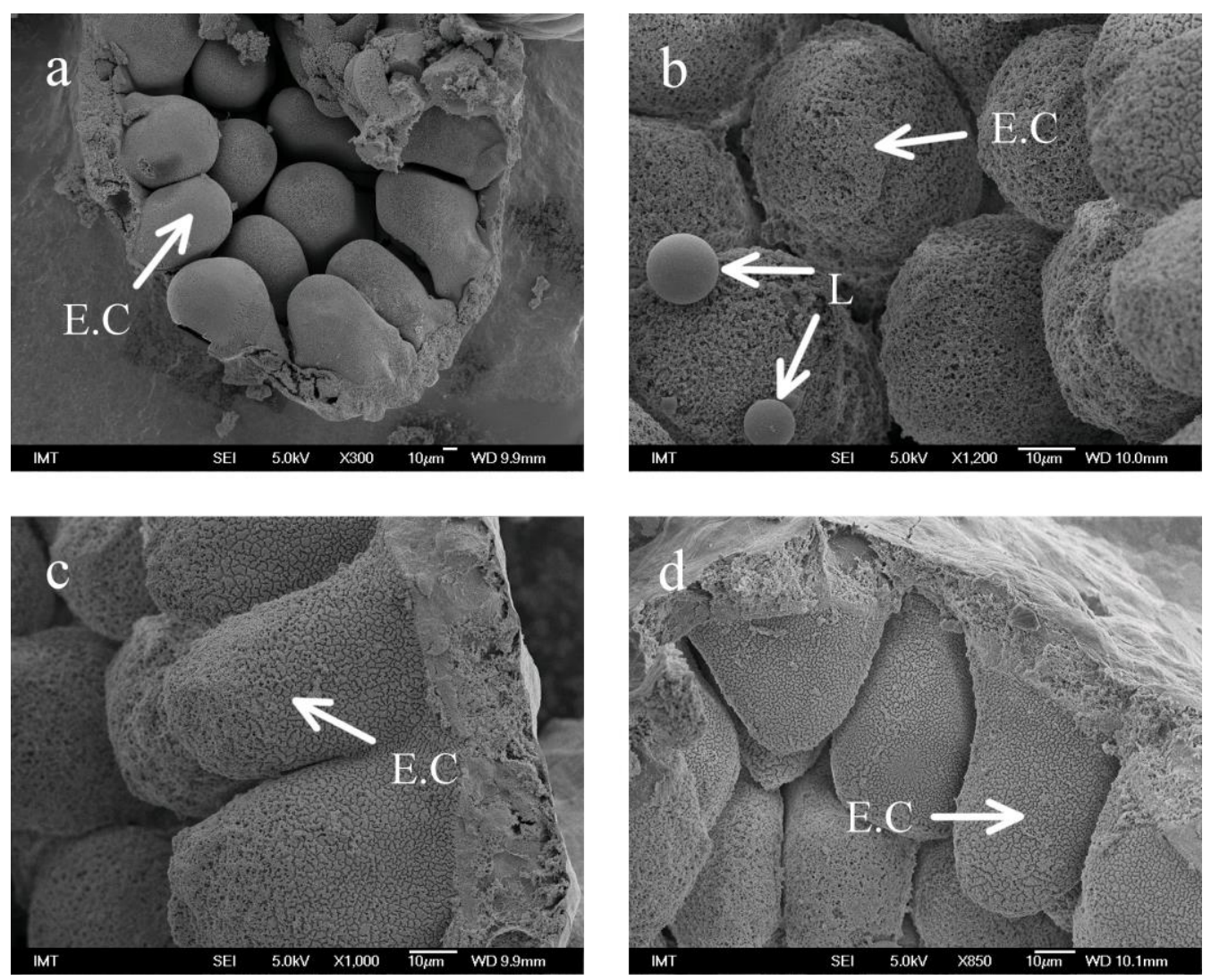

Figure 2. Normal appearance of cells in hepatopancreas . E.C- epithelial cells, L lipids, a) Normal shape and size of cells in hepatopankreas. b) Normal cells with some lipid drops, c and d) Normal shape and size with normal microvilli.

After an exposure period of two weeks the animals were dissected and the digestive glands (hepatopancreas) were isolated and prepared for scanning electron microscopy using the protocol for biological samples. The samples were coated with a layer $5-10 \mathrm{~nm}$ of gold/palladium alloy one by one for control and treated samples. The coating of samples was made with Precision etching coating system Gatan Model 682. Digestive tubes from the control group and exposed group were investigated by the scanning electron microscopy in order to find the changes and effect in the morphology of digestive gland epithelium. Investigations were performed on Institute of Metal and Technology,Ljubljana ( IMT) using model -JSM-6500F scanning electron microscopy with Field Emission source of electrons and presence of tungsten was detected by energy dispersive spectroscopy (EDS). 


\section{Results}

The woodlouse terrestrial isopoda $P$. scaber is used to test effects of nanofibers on the digestive tube (Figure 1c). Terrestrial isopods, including P. scaber, have become organisms of choice in (eco) toxicology and (eco) physiology.

The digestive system of $P$. scaber is composed of a stomach, a four digestive gland tubes (hepatopancreas) and a gut. The hepatopancreas (Figure 1d) has a big role in the metabolism and secretion (enzymes). Other role of hepatopancreas is to store the carbohydrates, lipids and to release them when the body needs them. Hepatopancreas is combined from big cells and small cells which alternate in the tube.

Tungsten nanofibers were present in the digestive gland epithelium of animals exposed to WOx nanofibers and they began to interact with the cells on some places. The interactions between tungsten nanofiber and cells membrane are presented in figure 3 a-d.

After two weeks of feeding the interactions in the digestive gland epithelium can be visible with scanning electron microscopy. The interaction begins when the nanofibers enter the digestive tube. The peristalsis, a radially symmetrical contraction and relaxation of muscles that propagates in a wave along the digestive tube, pushes forward the nanofibers. In case the length of nanofiber is similar to intercellular distance of gland epithelia cells the nanofiber can enter between the cells. During contraction periods the cells membrane are approached and nanofiber is pushed into membrane of neighbouring cells (figure $3 \mathrm{a}-\mathrm{d}$ ). This phenomenon was more common in the lower part of the digestive gland, probably depends from the weight and gravity. The surface of nanofiber was fast enveloped by organic matter. In case of thicker nanofiber, only organic envelop was damaged during further contraction periods as presented in figure $3 \mathrm{~d}$, and nanofiber remained pierced into the cells walls. The thinner nanofibers broke during the relaxation period and pierced the remaining parts in the cell membrane. The presence of WOx nanofibers was confirmed by EDS analysis (figure 4). 

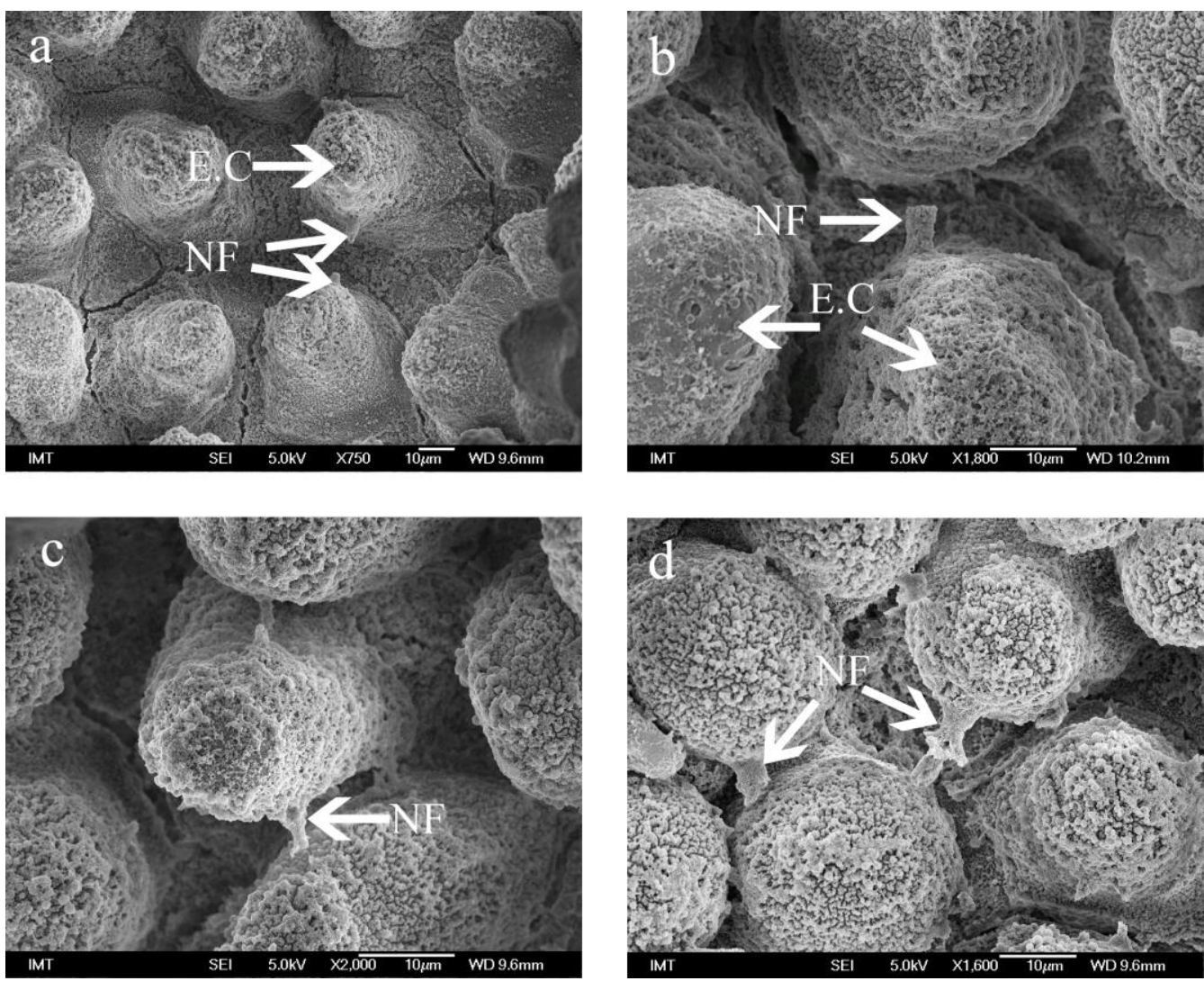

Figure 3. Interaction of nanofibers with epithelial cells. NF) WOx nanofibers, E.C) epithelial cells a) Part of nanofibers embedded into the cell membrane. b) Broken parts of nanofibers. c)

Nanofiber who is perforated deeply in the cell. d) Damaged nanofibers due peristalsis.

\section{Discussion}

To characterize nanofibers and its potential hazards sufficiently, empirical data are necessary. Since the early days of the REACH (Regulation (EC) No 1907/2006 of the European parliament and of the Council of 18 December 2006) proposals [13], it has been agreed by all partners that the number of animals used to gain toxicity information on chemicals should be kept to an absolute minimum.

Inflammation and fibrosis were observed on an organism level, whereas oxidative stress, antioxidant activity and cytotoxicity were observed effects on a cellular level [14]

The cell membrane, mitochondria and cell nucleus are considered as major cell compartments relevant for possible nanoparticle-induced toxicity [15]. When nanofibers interact with cell membranes, they cause defects such as physical disruptions, formation of holes and thinned 
regions. It was reported that cationic nano-objects pass through cell membranes by generating transient holes, a process undoubtedly associated with cytotoxicity [16]. It is known that a range of nanofibres and nanotubes affects at in vitro exposed systems the phagocytic ability of the cells [17].

It is widely recognized that the mechanisms of fibre induced lung injury with mineral fibres such as asbestos depend on several factors, e.g., length [18], diameter, chemical [19], and bio persistence [20]. Particles which enter the lung become coated with lung lining material, and are likely to modify the surface reactivity and hence the oxidant generating ability and phagocytises of the particles.

These findings revealed that SEM is a suitable method also for the observation of biological surfaces. The organism enveloped all nanofibers with organic coat after their entrance into digestive system. The interaction of nanofiber and its injury to digestive gland epithelia cells depends on the length of nanofiber. Also the pierced nanofibers were enveloped with organic coat. A small number of these phenomena (occurrence) and their position that the nanofibers cannot enter through the cells membrane without external force. The geometrical circumstances and contraction at peristalsis are the most important factors for the entrance of nanofiber through the cell membrane of digestive tube.

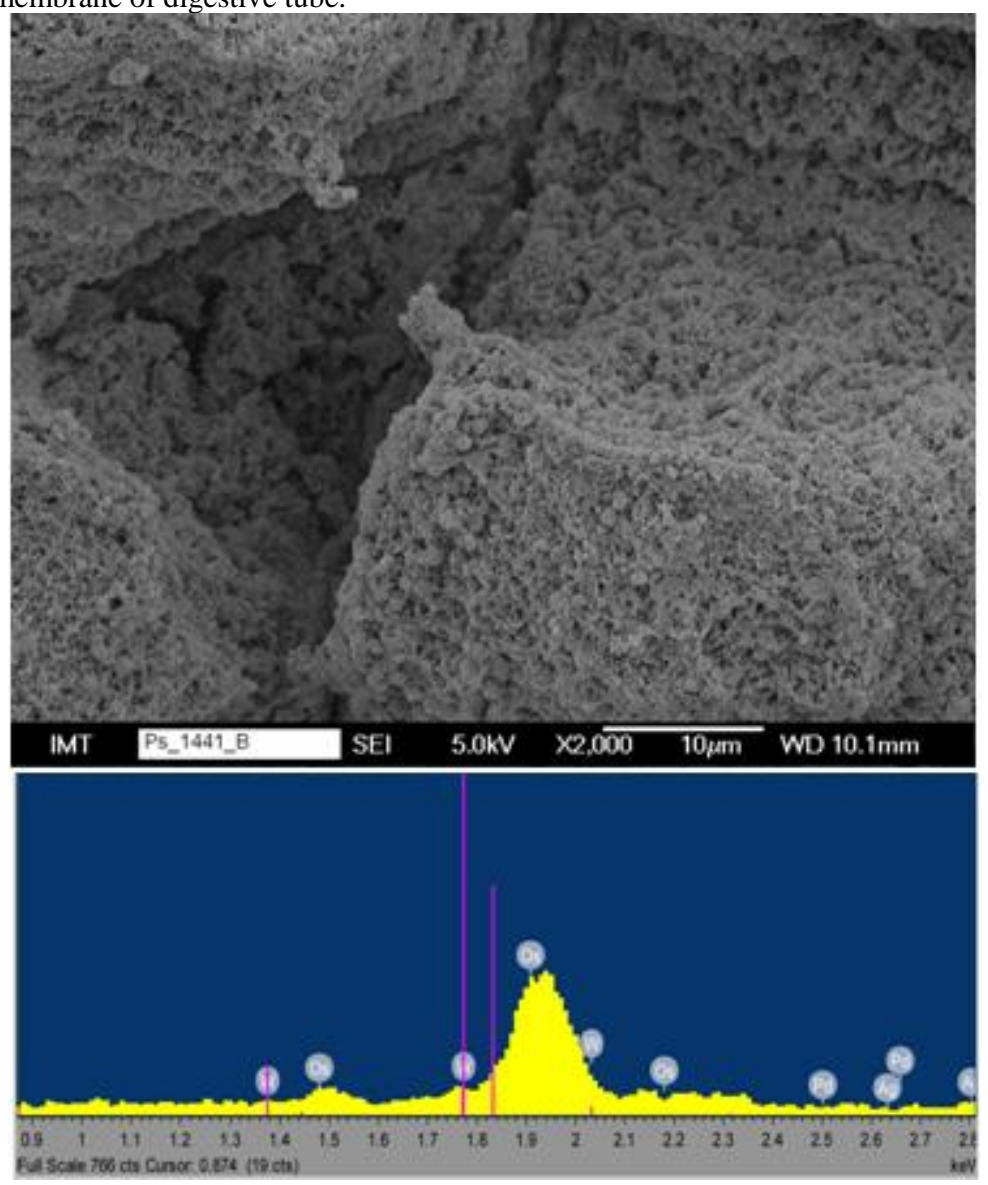

Figure 4. EDS spectra analysis of WOx nanofibers. 


\section{Acknowledgeements \\ The Ministry of High Education and Technology of Republic of Slovenia supported this work under grants P2-0050 Programme.}

\section{References}

1. Brumfiel, G.: Nanotechnology: A little knowledge, Nature. 246 (2003) $248-424$

2. Maynard, A.D., Aitken, R.J., Butz, T., Colvin, V., Donaldson, K., Oberdörster, G.: Safe handling of nanotechnology, Nature. 267 (2006) $269-444$

3. Nature Editorial.: Asbestos scandal, Irresponsible policies could cause an epidemic of malignant lung disease, Nature. 868 (2010) 874- 468

4. Maher, B.: News Feature, Epidemiology: Fear in the dust, Cancer epidemics in Turkey could hold the secret to staving off a public health disaster in North Dakota, Nature. 884 (2010) 885- 468

5. Scenihr.: Scientific committee on emerging and newly identified health risks. Opinion on the appropriateness of the risk assessment methodology in accordance with the technical guidance documents for new and existing substances for assessing the risks of nanomaterials

6. NANO Risk Framework.: Environmental Defense - DuPont Nano artnership.DuPont, Wimington,DE.http://www.edf.org/documents/6496_Nano\%20Risk\% 20Framework.pdf. 2007

7. Oberdörster, E., Oberdörster, J.: Nanotoxicology: an emerging discipline evolving from studies of ultrafine particles, Environ. Health Perspect.113 (2005) 823-839

8. Unfried, K., Albrecht, C., Klotz, L.O., Von Mikecz, A., Grether-Beck, S., Schins, R.P.F.: Cellular responses to nanoparticles: Target structures and mechanisms, Nanotoxicology.1 (2007) 52-71

9. Brown, D.M., Kinloch, I.A., Bangert, U., Windle, A.H., Walter, D.M., Walker,G.S., Scotchford, C.A., Donaldson, K., Stone, V.: An in vitro study of the potential of carbon nanotubes and nanofibres to induce inflammatory mediators and frustrated phagocytosis, Carbon. 45 (2007) 1743-1756

10. Verma, A., Uzun, O., Hu, Y.H., Hu, Y., Han, H.S., Watson, N., Chen, S.L., Irvine, D.J., Stellacci, F.: Surface-structure-regulated cell-membrane penetration by monolayer-protected nanoparticles, Nature Mater. 7 (2008) 588-595

11. Donaldson, K., Brown, G.M., Brown, D.M., Bolton, R.E., Davis, J.M.G.: The i nflammatory generating potential of long and short fibre amosite asbestos samples, Br. J Ind. Med. 46 (1989) 271-276

12. Lešer, V., Drobne, D., Vilhar, B., Kladnik, A., Žnidaršič, N., Štrus, J.: Epithelial thickness and lipid droplets in the hepatopancreas of Porcellio scaber (Crustacea: Isopoda) in different physiological conditions, Zoology. 111 (2008) 419-432

13. REACH .: Regulation (EC) No $1907 / 2006$ of the European parliament and of the Council of 18 December 2006 concerning the registration, evaluation, authorization and restriction of chemicals. http://ec.europa.eu/environment/chemicals/reach/reach_intro.htm. (2006) 
14. Donaldson, K.: Biological activity of respirable industrial fibres treated to mimic residence in the lung, Toxicol. Lett. 72 (1994) 299-305

15. Hassall, M., Turner, J.G., Rands, M.R.W.: Effects of terrestrial isopods on the decomposition of woodland leaf litter, Oecologia. 72 (1987) 597-604

16. Drobne, D., Strus, J.: The effect of $\mathrm{Zn}$ on the digestive gland epithelium of Porcellio scaber (Isopoda, Crustacea),Pflugers Archive - Eur. J. Physiol. 431(1996) 247-248

17. Žnidaršič, N., Štrus, J., Drobne, D.: Ultrastructural alterations of the hepatopancreas in Porcellio scaber under stress, Environ. Toxicol. Pharmacol. 13 (2003) 161-174

18. Drobne, D.: Terrestrial isopods - a good choice for toxicity testing of pollutants in the terrestrial environment, Environ. Toxicol. Chem. 16 (1997) 1159-1164

19. Paoletti, M.G., Hassall, M.: Woodlice (Isopoda: Oniscidea): their potential for assessing sustainability and use as bioindicators, Agric. Ecosyst. Environ. 7 (1999) $157-165$

20. Hassall, M., Zimmer, M., Loureiro, S.: Questions and possible new directions for research into the biology of terrestrial isopods, Eur. J Soil Biol. 41 (2005) 57-61 